\title{
Bacteriological profile and antimicrobial sensitivity pattern of isolates from diabetic foot of patients attending a teaching hospital in Northern India
}

\author{
Seema Aleem ${ }^{1}$, Harman Multani ${ }^{2}$, Humaira Bashir ${ }^{3}$ \\ ${ }^{1,3}$ Senior Resident, Department of Microbiology, Government Medical College, Srinagar, ${ }^{2}$ Senior Resident, Department \\ of Microbiology, Government Medical College, Jammu
}

Background: Diabetic foot ulcer is a major cause for diabetes related morbidity and hospitalization. Up to one-third of people with diabetes develop diabetic foot ulceration (DFU) during their lifetime and over $50 \%$ of these ulcerations become infected. Diabetic foot infections (DFIs) are associated with major morbidity, increasing mortality, high costs, increased risk of lower extremity amputation (LEA), and reduced quality of life. Aims and Objective: The current study was conducted to determine the microbiological profile and antibiotic susceptibility pattern of organisms in diabetic foot ulcers patients at a tertiary care center in Srinagar province. Materials and Methods: This was a Crosssectional, observational study conducted in diabetic patients with diabetic foot infection, randomly selected from outpatient departments (OPDs) and wards of Surgery and Medicine department, with Wagner grade 1-5 ulcers and irrespective of anti-diabetic treatment and diabetic foot injury treatment. Samples were processed and bacterial isolates were identified by standard microbiological procedures. Results: After following inclusion and exclusion criteria, 120 patients were considered for this study. In present study most common age group was 51-60 years age group (44\%) followed by $41-50$ years (32\%). $66 \%$ of participants were males. $55 \%$ patients had diabetes for more than 10 years. $43 \%$ patients had ulcer size less than $5 \mathrm{~cm}^{2}$. The most common category as per Wagner's classification was Grade 1, which comprised of $48 \%$ of study participants, followed by Grade $0(28 \%)$ and Grade $2(18 \%)$. Grade 3 and above comprised $7 \%$ of cases. Of the 120 study participants, $103(86 \%)$ showed growth on culture. Among these 62 $(60 \%)$ showed mono-microbial growth with 41 cases showing mixed growth. The most commonly isolated bacteria were Methicillin Resistant Staphylococcus aureus (MRSA) (23\%), Coagulase Negative Staphylococci (CoNS) (18\%), pseudomonas aeruginosa (18\%), Methicillin Sensitive-Staphylococci Aureus (9\%), Klebsiella Pneumoniae (9\%), and Escherichia Coli (8\%). Linezolid, vancomycin, clindamycin, gentamicin were most effective antimicrobial agents against gram positive bacteria. limipenem, piperacillin tazobactam, cefoperazone sulbactam \& gentamicin were most effective antimicrobial agents against gram negative bacteria. Conclusion: Early microbiological evaluation for bacteriological profile, the nature of the infection either monomicrobial or polymicrobial and antibiotic sensitivity testing can improve treatment outcome, reduces complications, morbidity as well as multidrug resistance.

Key words: Diabetic foot; Diabetic foot ulcer; Diabetic foot infection; Wagner's grading
Access this article online

Website:

http://nepjol.info/index.php/AJMS DOI: 10.3126/ajms.v12i5.34415 E-ISSN: 2091-0576 P-ISSN: 2467-9100

Copyright (c) 2021 Asian Journal of Medical Sciences

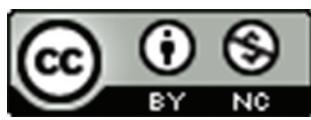

This work is licensed under a Creative Commons Attribution-NonCommercial 4.0 International License. 


\section{INTRODUCTION}

Diabetes mellitus is most common endocrine disorder with common affection towards kidney, nervous system and skin. ${ }^{1}$ Diabetes mellitus is a worldwide problem and its prevalence is increasing due to sedentary lifestyle, junk foods, obesity, early diagnosis, etc.

Metabolic abnormalities of insulin and elevated blood glucose level leads to multiple vascular, neurological and immunological abnormalities mainly affecting cardiovascular, renal and nervous systems, eyes and the skin. Diabetic foot injuriess arise mainly from skin ulceration associated with loss of protective sensation (peripheral neuropathy), altered foot architecture, and some forms of trauma. Various types of microorganisms colonize and proliferate on the wounds, which serve as a point of entry, causing tissue damage and infection. ${ }^{2}$

Diabetic foot ulcer is a major cause for diabetes related morbidity and hospitalization. It is estimated that approximately $20 \%$ of hospital admissions among diabetic patients are due to diabetic foot ulcers $\&$ related complications. ${ }^{3} \mathrm{Up}$ to one-third of people with diabetes develop a diabetic foot ulceration (DFU) during their lifetime and over $50 \%$ of these ulcerations become infected. ${ }^{4}$ Diabetic foot infections (DFIs) are associated with major morbidity, increasing mortality, high costs, increased risk of lower extremity amputation (LEA), and reduced quality of life.

Most of these infections are polymicrobiol in nature and mixed organisms are frequently encountered. However, the spectrum of microorganisms depends mainly on microbial flora of lower limb, metabolic factors, foot hygiene and the use of antibiotics. Diabetic foot infections may be extremely challenging to cure, due to late diagnosis (due to blunted clinical signs), presence of ischemia, difficult to-treat multidrug-resistant pathogens, and spread of infection to the bones, leading to osteomyelitis.

The present study was conducted to determine the microbiological profile and antibiotic susceptibility pattern of organisms in diabetic foot ulcers patients at a tertiary care center in Srinagar province

\section{MATERIAL AND METHODS}

Present study was a cross-sectional, observational study conducted in the Department of Microbiology, Government Medical College and Hospital, Srinagar. Study period was September 2018 to August 2019 (1 year).
Inclusion criteria was all diabetic patients with diabetic foot infection were randomly selected from outpatient departments (OPDs) and wards of Surgery and Medicine department, with Wagner grade 1-5 ulcers and irrespective of anti-diabetic treatment and diabetic foot injury treatment, willing to participate in study.

Exclusion criteria were those patients who were sseriously ill, patients with neuropathy other than diabetic neuropathy, patients with acute limb ischemia, patients not willing to participate and inadequately collected sample.

Study was explained to patients and a written informed consent was taken from patients. The clinical details of the patients such as age, sex, types of diabetes, duration of diabetes, size of ulcer and duration of ulcer were recorded. The ulcers were graded according to the Wagner's grade classification.

Samples (pus, debrided ulcer material or aspirate of material from infected wound) from the infected foot lesions were collected aseptically by using sterile cotton swab. Sterile cotton swab sticks were moistened with sterile normal saline before collecting the specimens. The swab sticks were extended deeply into the depth of the lesion avoiding touching of surrounding skin area around the wound. The collected samples were immediately transported to the microbiology department.

Samples were processed \& bacterial isolates were identified by standard microbiological procedures (Macroscopic evaluation, Microscopic examination, culture, motility and biochemical test) and antibiotic susceptibility testing was performed through the Kirby Bauer's disc diffusion method.

Results of the culture and antimicrobial sensitivity testing were documented. Collected data was entered in Microsoft excel sheet $\&$ analysed. Statistical analysis was done using descriptive statistics.

\section{RESULTS}

After applying inclusion \& exclusion criteria, total 120 patients was considered for study. In present study most common age group was 51-60 years age group (44\%) followed by $41-50$ years (32\%). Male patients $(66 \%)$ were more than female $(39 \%)$. Male to female ratio was 1.9:1. History of trauma (48\%), family history of diabetes (26\%), hypertension (19\%), smoking (18\%) \& alcohol consumption $(16 \%)$ were common risk factors in study patients. $55 \%$ patients had diabetes for more than 10 years. $43 \%$ patients had ulcer size less than $5 \mathrm{~cm}^{2}$ (Table 1). 
The most common category as per Wagner's classification was Grade 1, which comprised of $48 \%$ of study participants, followed by Grade $0(28 \%)$ and Grade $2(18 \%)$. Grade 3 and above comprised $7 \%$ of cases (Table 2).

\section{Microbiological profile}

Of the 120 study participants, 103 (86\%) showed growth on culture. Among these $62(60 \%)$ showed mono-microbial growth with 41 cases showing mixed growth. The most commonly isolated bacteria were Methicillin Resistant Staphylococcus Aureus (MRSA) (23\%), Coagulase Negative Staphylococi (CoNS) (18\%), pseudomonas Aeruginosa (18\%), Methicillin Sensitive-Staphylococci Aureus (9\%), Klebsiella Pneumoniae (9\%), and Escherichia Coli (8\%) (Table 3).

In vitro sensitivity of antimicrobial agents against Gram positive bacteria was done. Linezolid, vancomycin,

\begin{tabular}{|c|c|c|}
\hline Characteristics & No of patients & Percentage \\
\hline \multicolumn{3}{|l|}{ Age Group (in years) } \\
\hline $21-30$ & 1 & $1 \%$ \\
\hline $31-40$ & 3 & $3 \%$ \\
\hline $41-50$ & 38 & $32 \%$ \\
\hline $51-60$ & 53 & $44 \%$ \\
\hline $61-70$ & 17 & $14 \%$ \\
\hline $71-80$ & 8 & $7 \%$ \\
\hline Mean Age(years) & \multicolumn{2}{|c|}{$52.7 \pm 11.3$} \\
\hline \multicolumn{3}{|l|}{ Sex } \\
\hline Male & 79 & $66 \%$ \\
\hline Female & 41 & $34 \%$ \\
\hline \multicolumn{3}{|l|}{ Risk factors } \\
\hline History of trauma & 58 & $48 \%$ \\
\hline Family History of diabetes & 31 & $26 \%$ \\
\hline Hypertension & 23 & $19 \%$ \\
\hline Smoking & 21 & $18 \%$ \\
\hline Alcohol consumption & 19 & $16 \%$ \\
\hline \multicolumn{3}{|l|}{ Duration of diabetes mellitus } \\
\hline$<5$ years & 19 & $16 \%$ \\
\hline $5-10$ yrs. & 35 & $29 \%$ \\
\hline$>10$ years & 66 & $55 \%$ \\
\hline \multicolumn{3}{|l|}{ Size of ulcer (in $\mathrm{cm}^{2}$ ) } \\
\hline$<5$ & 51 & $43 \%$ \\
\hline $5-20$ & 43 & $36 \%$ \\
\hline$>20$ & 26 & $22 \%$ \\
\hline
\end{tabular}

\begin{tabular}{|c|c|c|c|}
\hline Grade & Clinical signs & Number & $\%$ \\
\hline 0 & Intact skin & 33 & 28 \\
\hline 1 & $\begin{array}{l}\text { Superficial ulcer of skin/ subcutaneous } \\
\text { tissue }\end{array}$ & 58 & 48 \\
\hline 2 & $\begin{array}{l}\text { Ulcer extending to tendon/ bone/ } \\
\text { capsule }\end{array}$ & 21 & 18 \\
\hline 3 & Deep ulcer with osteomyelitis/ abscess & 5 & 4 \\
\hline 4 & $\begin{array}{l}\text { Gangrene of toes/ forefoot/ localized } \\
\text { gangrene }\end{array}$ & 3 & 3 \\
\hline 5 & $\begin{array}{l}\text { Mid foot/ hind foot gangrene } \\
\text { TOTAL }\end{array}$ & $\begin{array}{c}0 \\
120\end{array}$ & 0 \\
\hline
\end{tabular}

clindamycin, gentamicin were most effective antimicrobial agents against methicillin resistant staphylococcus aureus (MRSA), coagulase negative staphylococci (CoNS) and methicillin sensitive-staphylococci aureus (9\%) (Table 4).

In vitro sensitivity of antimicrobial agents against gram negative bacteria imipenem, piperacillin tazobactam, cefoperazone sulbactam \& gentamicin were most effective antimicrobial agents against pseudomonas aeruginosa, klebsiella pneumoniae and escherichia coli.

\section{DISCUSSION}

Diabetic foot ulcers are not spontaneous ulcers, but results from the interplay of various factors line neuropathy, autonomic neuropathy, and peripheral vascular disease, superimposed with alterations in the plantar pressure, defective footwear and limited joint mobility.

Majority of diabetic foot injuries in India are due to sociocultural practices such as barefoot walking, religious practices like walking on fire, use of improper footwear and lack of knowledge regarding foot care attributes towards increase in the prevalence of diabetic foot. ${ }^{5}$ The combination of insensate foot secondary to neuropathy and deformation predispose the diabetic patients to ulcers formation. The ulcers are colonised by the bacteria and when the overgrowth of the pathogens triggers the deleterious inflammation or tissue destruction, it is termed as an infection. ${ }^{6}$

Hyperglycemia, neuropathy, peripheral arterial disease, foot deformity, foot trauma, impaired immunologic response and infections are the major predisposing factors leading to

\begin{tabular}{lcc} 
Table 3: Bacterial isolates & & \\
\hline Organism isolated & Number & Percentage \\
\hline Gram positive organisms (60\%) & & \\
Methicillin resistant Staphylococcus & 27 & $23 \%$ \\
aureus & 21 & $18 \%$ \\
Coagulase Negative Staphylococci & 11 & $9 \%$ \\
Methicillin sensitive-Staphylococci & & \\
aureus & 8 & $7 \%$ \\
Group B Streptococci & 5 & $4 \%$ \\
Enterococcus faecalis & & \\
Gram negative organisms (49\%) & 22 & $18 \%$ \\
Pseudomonas aeruginosa & 11 & $9 \%$ \\
Klebsiella pneumoniae & 10 & $8 \%$ \\
Escherichia coli & 8 & $7 \%$ \\
Acinetobacter baumanii & 5 & $4 \%$ \\
Citrobacter sp & 3 & $3 \%$ \\
Proteus sp & & \\
No growth & 17 & $14 \%$ \\
Bacterial flora & & \\
Monomicrobial & 62 & $60 \%$ \\
Polymicrobial & 41 & $40 \%$ \\
\hline
\end{tabular}




\begin{tabular}{|c|c|c|c|}
\hline \multirow[t]{2}{*}{ Antimicrobial agent } & \multicolumn{3}{|c|}{ Sensitive organisms } \\
\hline & $\begin{array}{c}\text { Methicillin resistant } \\
\text { Staphylococcus aureus }(n=27)(\%)\end{array}$ & $\begin{array}{c}\text { Coagulase Negative } \\
\text { Staphylococci }(n=21)(\%)\end{array}$ & $\begin{array}{c}\text { Methicillin sensitive-Staphylococci } \\
\text { aureus }(n=11)(\%)\end{array}$ \\
\hline Linezolid & $27(100 \%)$ & $20(96 \%)$ & $11(100 \%)$ \\
\hline Vancomycin & $26(96 \%)$ & $21(100 \%)$ & $9(82 \%)$ \\
\hline Clindamycin & $22(81 \%)$ & $19(90 \%)$ & $11(100 \%)$ \\
\hline Gentamicin & $17(63 \%)$ & $12(57 \%)$ & $8(73 \%)$ \\
\hline Cotrimoxazole & $16(59 \%)$ & $11(52 \%)$ & $5(45 \%)$ \\
\hline Ciprofloxacin & $14(52 \%)$ & $8(38 \%)$ & $7(64 \%)$ \\
\hline Erythromycin & $11(41 \%)$ & $12(57 \%)$ & $8(73 \%)$ \\
\hline Penicillin & $3(11 \%)$ & $4(19 \%)$ & $4(36 \%)$ \\
\hline Ampicillin & $3(11 \%)$ & $1(5 \%)$ & $5(45 \%)$ \\
\hline
\end{tabular}

limb threatening diabetic foot ulcers and are responsible for increased duration of hospitalization, cost of management, morbidity and mortality among diabetic patients.

For the treatment of DFI, the combination of debridement and antibiotics, coupled with good nutrition and diabetic control is paramount. ${ }^{7}$ According to recommendations by the Infectious Disease Society of America (IDSA), empirical antimicrobial treatment should be initiated until the causative pathogens and their antibiotic susceptibility is known. ${ }^{8}$

Jain et $\mathrm{al},{ }^{9}$ in their study had $81 \%$ males and $18 \%$ females. Higher male prevalence may be due to the higher level of outdoor physical activity with inadequate and improper feet care among males in comparison to females. The results were in concurrence with the findings of the current study. In a study by Mohite et al, ${ }^{10} 53.80 \%$ of the cases had ulcers of Grade III and IV, whereas 12 patients had extensive gangrene (i.e., Grade V). 67.9\% with majority of lesions located over sole area. These findings are consistent with present study.

In a recent Indian study of diabetic Foot Infections, bacterial etiology could be identified among 228 cases out of 253 (90\%); single organism was isolated in 206 (90.3\%) among which CONS and S. aureus being the most common, followed by E. coli and Pseudomonas. Similar results are noted in present study. ${ }^{11}$ Otta $\mathrm{S}$ et $\mathrm{al},{ }^{12}$ had $62.2 \%$ of wound cultures showed monomicrobial flora and $27.1 \%$ had polymicrobial flora. In present study monomicrobial flora (61\%) were more than with polymicrobial (39\%). Gram positive isolates were more common than gram negative isolates in our study which is similar to the findings of Baba $\mathrm{M}$ et al, ${ }^{13}$ and Malepati S et al. ${ }^{14}$

Staphylococcus aureus and Pseudomonas aeruginosa are important causative microorganisms in DFIs. The distributions of these causative organisms differ geographically and according to the illness duration, prior antibiotic use, and the relevance of nosocomial infections. ${ }^{14}$ Also, the use of inappropriate antibiotics has become a problem for multidrug resistant bacteria, making the selection of antibiotics difficult. ${ }^{15}$

Factors responsible for MDR may be frequent hospitalization, recent use of broad-spectrum antibiotics, inadequate surgical source reduction, chronic wounds, irrational use of antibiotics, and the transfer of resistance genes by transport means. ${ }^{9}$ There is a recent emergence of the NDM metallo-beta-lactamase (MBL) encoding genes among different enterobacterial species and also in nonfermenters like $P$. aeruginosa and Acinetobacter baumannii in various parts of world including India. ${ }^{16,17}$

Most commonly encountered multi drug resistant organisms are methicillin-resistant Staphylococcus aureus (MRSA), vancomycin resistant Enterococci (VRE) and Gram-negative bacteria producing extended-spectrum beta-lactamases (ESBL), Metallo beta-lactamases (MBL). Large and deep ulcer, previous hospitalization and poor glycemic control are identified as some of the risk factors responsible for developing an infection with these drugresistant microorganisms. ${ }^{18}$

Large, prospective, multicenter studies are required to assess the appropriate antibiotic regimen in diabetic foot ulcers and proper management of antibiotics must be implemented to decrease the incidence and development of multi drug resistant organisms.

\section{CONCLUSION}

Diabetic foot injuries \&/or ulcer are a serious concern in patients with uncontrolled diabetics and require team approach for proper management. Early microbiological evaluation for bacteriological profile, the nature of the infection either monomicrobial or polymicrobial $\&$ antibiotic sensitivity testing can improve treatment outcome, reduces complications, morbidity as well as 
multidrug resistance. Appropriate usage of antibiotics based on local antibiogram pattern can certainly help the clinician in reducing the burden of DFIs, which ultimately reduces the rate of amputations.

\section{ACKNOWLEDGEMENT}

The authors take this opportunity to thank the Department of Surgery, Medicine and Microbiology for their support for this study

\section{REFERENCES}

1. American Diabetes Association. Diagnosis and classification of diabetes mellitus. Diabetes Care 2009; 32:62-67.

https://doi.org/10.2337/dc09-S062

2. Lipsky BA, Berendt AR, Cornia PB, Pile JC, Peters EJ, Armstrong DG, et al. Infectious Diseases Society of America. 2012 Infectious Diseases Society of America clinical practice guideline for the diagnosis and treatment of diabetic foot infections. Clin Infect Dis 2012; 54:e132-e173.

https://doi.org/10.1093/cid/cis346

3. Aalaa M, Malazy OT, Sanjari $M$, Peimani $M$ and Mohajeri- Tehrani MR. Nurses' role in diabetic foot prevention and care; a review. Journal of Diabetes \& Metabolic Disorders. 2012; 11(1):24.

https://doi.org/10.1186/2251-6581-11-24

4. Armstrong DG, Boulton AJM and Bus SA. Diabetic foot ulcers and their recurrence. N Engl J Med. 2017; 376:2367-2375. https://doi.org/10.1056/NEJMra1615439

5. Raspovic KM and Wukich DK. Self-reported quality of life and diabetic foot infections. J Foot Ankle Surg. 2014; 53:716-719. https://doi.org/10.1053/j.ffas.2014.06.011

6. Spichler A, Hurwitz BL, Armstrong DG and Lipsky BA. Microbiology of diabetic foot infections: from Louis Pasteur to 'crime scene investigation'. BMC Medicine. 2015; 13:2.

https://doi.org/10.1186/s12916-014-0232-0

7. Son ST, Han S, Lee TY, Namgoong $S$ and Dhong E. The microbiology of diabetic foot infections in Korea. J Wound Management Res. 2017; 13(1): 8-12. https://doi.org/10.22467/jwmr.2017.00108

8. Lipsky BA, Berendt AR, Cornia PB, Pile JC, Peters EJ,
Armstrong DG, et al. Infectious Disease Society of America clinical practice guideline for the diagnosis and treatment of diabetic foot infections. Clin Infect Dis. 2012; 54(12): e132-e173. https://doi.org/10.1093/cid/cis346

9. Jain SK and Barman R. Bacteriological profile of diabetic foot ulcer with special reference to drug-resistant strains in a tertiary care center in North-East India. Indian J Endocr Metab. 2017; 21:688-694.

https://doi.org/10.4103/ijem.IJEM_546_16

10. Mohite R, Karande GS and Chavan SK. Clinicobacteriological profile of diabetic foot ulcer among the patients attending rural tertiary health center. Int J Med Res Health Sci. 2014; 3:861-865. https://doi.org/10.5958/2319-5886.2014.00015.0

11. Vasanthan $K$, Vengadakrishnan $\mathrm{K}$ and Surendran $\mathrm{P}$. Clinical Profile of Diabetic Foot Infections. Int J Sci Stud. 2018; 6(1):24-27.

12. Otta S, Debata NK and Swain B. Bacteriological profile of diabetic foot ulcers. CHRISMED J Health Res. 2019; 6:7-11. https://doi.org/10.4103/cjhr.cjhr_117_17

13. Baba M, Davis WA, Norman PE and Davis TME. Temporal changes in the prevalence and associates of foot ulceration in type 2 diabetes: the Fremantle Diabetes Study. J Diabetes Complications. 2015; 29(3):356-361. https://doi.org/10.1016/j.jdiacomp.2015.01.008

14. Malepati S, Vakamudi P, Kandati J and Sreeram S. Bacteriological study of diabetic foot ulcer according to Wagner's classification: a one-year study. Int Surg J. 2018; 5:98-104. https://doi.org/10.18203/2349-2902.isj20175534

15. Uckay I, Gariani K, Pataky Z and Lipsky BA. Diabetic foot infections: state-of-the-art. Diabetes Obes Metab. 2014; 16:305-316. https://doi.org/10.1111/dom.12190

16. Shanthi M, Sekar U, Kamalanathan A and Sekar B. Detection of New Delhi metallo beta lactamase-1 (NDM-1) carbapenemase in Pseudomonas aeruginosa in a single centrein southern India. Indian J Med Res. 2014; 140:546-550.

17. Kumarasamy KK, Toleman MA, Walsh TR, Bagaria J, Butt F, Balakrishnan R, et al. Emergence of a new antibiotic resistance mechanism in India, Pakistan, and the UK: a molecular, biological, and epidemiologicalstudy. Lancet Infect Dis. 2010; 10:597-602. https://doi.org/10.1016/S1473-3099(10)70143-2

18. Gupta S, Attri A, Khanna S, Chander J and Mayankjayant. Outcome in Patients of Diabetic Foot Infection with Multidrug Resistant Organisms. J Foot Ankle Surg (Asia Pacific). 2018; 5(2):51-55.

https://doi.org/10.5005/jp-journals-10040-1089

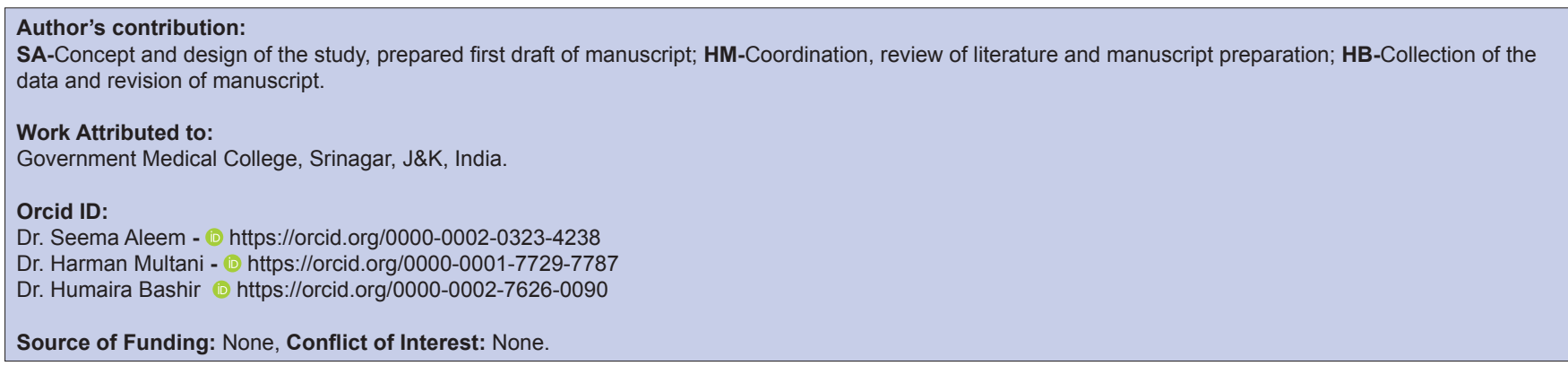

